\title{
Disorders of consciousness: What's in a
} \section{name?}

\author{
Olivia Gosseries ${ }^{1}$, Marie-Aurélie Bruno ${ }^{1}$, Camille Chatelle, Audrey Vanhaudenhuyse, \\ Caroline Schnakers, Andrea Soddu and Steven Laureys* \\ Coma Science Group, Cyclotron Research Centre \& Neurology Department, University and University Hospital of \\ Liège, Liège, Belgium
}

\begin{abstract}
Following a coma, some patients may "awaken" without voluntary interaction or communication with the environment. More than 40 years ago this condition was coined coma vigil or apallic syndrome and later became worldwide known as "persistent vegetative state". About 10 years ago it became clear that some of these patients who failed to recover verbal or non-verbal communication did show some degree of consciousness - a condition called "minimally conscious state". Some authors questioned the usefulness of differentiating unresponsive "vegetative" from minimally conscious patients but subsequent functional neuroimaging studies have since objectively demonstrated differences in residual cerebral processing and hence, we think, conscious awareness. These neuroimaging studies have also demonstrated that a small subset of unresponsive "vegetative" patients may show unambiguous signs of consciousness and command following inaccessible to bedside clinical examination. These findings, together with negative associations intrinsic to the term "vegetative state" as well as the diagnostic errors and their potential effect on the treatment and care for these patients gave rise to the recent proposal for an alternative neutral and more descriptive name: unresponsive wakefulness syndrome. We here give an overview of PET and (functional) MRI studies performed in these challenging patients and stress the need for a separate ICD-9-CM diagnosis code and MEDLINE MeSH entry for "minimally conscious state" as the lack of clear distinction between vegetative state/unresponsive wakefulness syndrome and minimally conscious state may encumber scientific studies in the field of disorders of consciousness.
\end{abstract}

Keywords: Consciousness, vegetative state/unresponsive wakefulness syndrome, minimally conscious state, functional MRI, positron emission tomography

\section{Introduction}

Since the invention of the artificial respirator in the 1950s by Bjorn Ibsen in Denmark, many patients who previously did not survive their brain damage and coma now could be artificially ventilated and had their cardiac circulation sustained. This lead to the redefinition of

\footnotetext{
${ }^{1}$ Contributed equally.

* Corresponding author: Pr Steven Laureys, Coma Science Group, Cyclotron Research Center, Neurology Dept, University and University Hospital of Liège, Sart-Tilman B30, 4000 Liège, Belgium. Tel.: +32 436623 16; Fax: +32 436629 46; E-mail: steven.laureys@ ulg.ac.be.
}

death based on neurological criteria (i.e., brain death) and the notion of therapeutic obstinacy (i.e., the continuation or start of treatment in the absence of any hope of recovery). It also leads to an increased incidence of patients "awakening" from the acute coma while remaining without any sign of voluntary interaction with the environment. Some days to weeks after the acute brain insult (often also after a period of sedation or anesthesia/pharmacological coma) these patients classically open the eyes, start to breath unaided and show spontaneous or stimulus-induced "reflex" or "automatic" movements. This condition was initially named apallic syndrome [46] or coma vigil [21] and in 1972 was coined "persistent vegetative state (PVS)" [43] a 
term now also called "unresponsive wakefulness syndrome" (UWS) [55]. We here discuss the diagnostic challenges encountered in patients with disorders of consciousness (DOC) and the lessons learned from positron emission tomography (PET) and magnetic resonance imaging (MRI) studies in "resting state", passive sensory stimulation and active "command following" and "communication" paradigms.

\section{A rose by any other name would smell as sweet}

The name vegetative state (VS) was chosen to refer to the preserved vegetative nervous functioning, meaning these patients have (variably) preserved sleep-wake cycles, respiration, digestion or thermoregulation. The term "persistent" was added to denote that the condition remained for at least one month after insult. In 1994, the Multi-Society Task Force on PVS defined the temporal criteria for irreversibility (that is, more than one year for traumatic and three months for non-traumatic (anoxic) etiology) and introduced the notion of permanent vegetative state [102]. It is to these latter cases that often ethical and legal end-of-life issues, of withholding and withdrawal of life sustaining treatment (that is, artificial hydration and nutrition), are related [23,42]. Unfortunately the abbreviation for Persistent Vegetative State (i.e., PVS) is time and again confounded with the abbreviation for Permanent Vegetative State [49, 56]. In line with the recommendations of the American Congress of Rehabilitation Medicine [1], we prefer to avoid the use of the terms "persistent" and "permanent" in favor of simply specifying the etiology and length of time patients spent in a vegetative/unresponsive condition.

Very recently the European Task Force on Disorders of Consciousness has proposed a more descriptive and neutral term for VS: "Unresponsive Wakefulness Syndrome" (UWS) [55]. "Unresponsive" was chosen to illustrate that these patients only show reflex movements without response to commands. "Wakefulness" refers to the presence of eye opening - spontaneous or stimulation induced - never observed in coma. "Syndrome" stresses that we are assessing a series of clinical signs. Indeed, consciousness is a subjective first person experience and its clinical evaluation is based on the assessment of motor responsiveness. Table 1 shows a list of translations for "unresponsiveness" or UWS permitting medical caregivers an alternative name for "vegetative". The reason for changing the name was mainly justified by the intrinsic negative connotation of the
Table 1

Translations of unresponsive wakefulness syndrome (UWS), the recently proposed alternative name for "vegetative state" (VS) [55]

\begin{tabular}{ll}
\hline Language & Proposed term \\
\hline English & unresponsive wakefulness syndrome \\
French & syndrome d'éveil non répondant \\
Dutch & niet responsief waaksyndroom \\
German & syndrom des nicht-responsiven wachzustandes \\
Spanish & síndrome de vigilia sin respuesta \\
Italian & sindrome di vigilanza non responsiva \\
Greek & $\sigma \nu \delta \rho o \mu$ $\mu \eta \quad \alpha \pi$ $\quad$ $\rho \sigma \iota \mu \eta \varsigma \quad \varepsilon \rho \gamma o \rho \sigma \eta \varsigma$ \\
Portuguese & síndrome de vigília não respondent \\
Danish & uresponsiv vågenhedsyndrom \\
Swedish & oresponsiv vakenhetsyndrom \\
Norwegian & uresponsiv våkenhetsyndrom \\
\hline
\end{tabular}

word "vegetative" (unintentionally comparing patients to vegetables) but also by the problems of quantifying consciousness at the bedside (as illustrated by clinical studies assessing possible misdiagnosis) and by neuroimaging studies showing in some (very) rare patients residual cognition inaccessible to behavioral examination. How difficult is it to make the clinical diagnosis of VS/UWS?

\section{Making the bedside diagnosis}

Clinical studies conducted in the early 1990s have illustrated how challenging it can be to disentangle reflex behavior (characteristic of vegetative/unresponsive patients) from intermittent voluntary behavior (characteristic of minimally conscious patients) - a problem that can potentially lead to diagnostic error in up to $40 \%$ of patients [3,24]. A recent study by Schnakers et al has demonstrated that despite the publication of numerous clinical guidelines on the diagnostic criteria of VS $[4,85,103]$, and despite the publication of diagnostic criteria for MCS [36], these high rates of diagnostic error seemingly remain unchanged when the diagnosis is based on unstructured neurological assessment [96]. In our view, the lessons to learn from these studies on "misdiagnosis" of VS/UWS illustrate the need for standardized "consciousness-scales". It has indeed been shown that the use of validated scales such as the Coma Recovery Scale - Revised (CRS-R) [38] or the Sensory Modality Assessment and Rehabilitation Technique (SMART) [39] permit to identify small, fluctuating and often easily exhaustible motor signs of conscious awareness that can be missed by unstructured clinical assessment [96], or by using acute "coma scales" such as the Glasgow Coma Scale [93] - for review see [2]. 
Scales like the CRS-R [38] and SMART [39] offer the advantage to systematically search for signs of non-reflex behavior (e.g., visual pursuit or oriented response to noxious stimulation) and command following in a well-defined manner. Visual pursuit, for example, should be assessed by using a moving mirror, as it has been shown that a substantial number of patients will not show eye tracking of a moving object or person, but will do so when using an auto-referential stimulus such as the own face [109]. Conversely, signs such as visual blinking to threat [107] and visual fixation [20] were recently shown not to necessarily reflect conscious awareness and could hence be compatible with the diagnosis of VS/UWS. Finally, the absence of (behavioral) proof of consciousness is not absolute proof of absence of consciousness [70]. It is important that the evaluations are repeated over time and performed by trained experienced assessors. Confounding factors such as drugs with sedative side effects (e.g., against spasticity or epilepsy) or the presence of infection or other medical complications should be accounted for. This situation is even more problematical when patients have underlying deficits with communication functions, such as aphasia, agnosia or apraxia [18,69]. Hence, some behaviorally unresponsive patients could, despite the best clinical assessment, be underestimated in terms of residual cognition or conscious awareness [52]. Since the venue of functional neuroimaging, this challenging issue can be addressed by directly measuring brain activity at rest and during sensory stimulation in these patients (for review see [54,88, 105]).

\section{Measuring the brain "at rest"}

Historically, the first reliable studies employed positron emission tomography (PET) quantifying the brain's metabolism in resting conditions by use of 18fluorodeoxyglucose (FDG). These early studies needed more invasive methods (repeated arterial blood sampling) to calculate cerebral metabolic rates for glucose metabolism (expressed in $\mathrm{mg}$ of glucose use per $100 \mathrm{gr}$ of brain tissue per minute). As summarized in Table 2A, they showed a global and massive decrease in brain activity in VS/UWS [28,61,67,86,104]. However, the reported decrease in global cortical brain metabolism showed some variability with reductions ranging from 25 to $72 \%$ of normal values (obtained in healthy waking volunteers). The advent of more sophisticated and data-driven (i.e., voxel-based) statisti- cal analytical tools next permitted to recognize not only global changes in brain function but more detailed regional differences in metabolic activity distinctive of VS/UWS.

Early voxel-based comparisons $[61,62,68]$ between patients (i.e., wakeful "unawareness") and age-matched healthy controls (i.e., wakeful awareness) demonstrated that VS/UWS patients systematically showed a metabolic dysfunction in a widespread fronto-parietal network encompassing midline (i.e., anterior cingulate/mesiofrontal and posterior cingulate/precuneus) and lateral (i.e., prefrontal and posterior parietal) associative cortices. As was expected, the relatively preserved areas were confined to subcortical, midbrain and brainstem structures known to be involved in autonomous functions such as sleep-wake cycles, thermoregulation and respiration [50]. Recent studies by our and other groups have confirmed these results [10, 20,44,75,98]. These observations made us postulate that consciousness should not be seen as an emergent property of whole brain function but rather critically depends on the functional integrity of a neuroanatomically widespread but well-defined frontoparietal network [5, 48]. Subsequent functional neuroimaging studies on conscious perception in healthy volunteers $[29,83]$ as well as data obtained in sleep (for review see [71]) and general anesthesia (for review see [17]) have confirmed this "frontoparietal workspace" hypothesis of consciousness. User-independent "consciousness classifiers" [80] can now use patients' FDG-PET brain scans, automatically assess the functional integrity in the frontoparietal network and calculate a probability of being VS/UWS or conscious but "locked-in" - illustrating the translation of scientific knowledge from the bench to the bedside.

Within this frontoparietal "awareness network" the precuneus/posterior cingulate cortex seems to be a "critical hub" [110,111]. Indeed, this area is the most active in conscious resting conditions [82] and seems the most impaired in altered states of consciousness, differentiating VS/UWS from MCS (for review see [66]). Importantly, recovery from VS/UWS seems to be paralleled by the restoration of metabolic activity in the precuneus/posterior cingulate region $[53,62]$. Similarly, late recovery from MCS was paralleled by axonal regrowth in this region as measured by MRI diffusion tensor imaging [112]. However, we should not make the mistake to reduce a cognitive function to a brain area or network. In addition to the (neophrenological) concept of cerebral functional segregation we stress the importance of functional integration or connectivity. 
Table 2

"Resting state" brain function as measured by (A) positron emission tomography (PET) 18fluorodeoxyglucose (FDG) and (B) functional magnetic resonance imaging (fMRI) in disorders of consciousness

\begin{tabular}{|c|c|c|c|c|c|}
\hline Reference & $\mathrm{N}$ & Diagnosis & Etiology & Duration & Main findings \\
\hline \multicolumn{6}{|l|}{ A. PET } \\
\hline Levy et al., 1987 [67] & 7 & VS/UWS & TBI/NTBI & $1-72 \mathrm{~m}$ & $60 \%(53-67 \%)$ decrease in metabolism \\
\hline De Volder et al., 1990 [28] & 7 & VS/UWS & NTBI & $1-4 \mathrm{~m}$ & $53 \%(43-65 \%)$ decrease in metabolism \\
\hline Tommasino et al., 1995 [104] & 10 & VS/UWS & TBI/NTBI & $2-24 \mathrm{~m}$ & $56 \%$ decrease in metabolism \\
\hline Rudolf et al., 1999 [86] & 24 & VS/UWS & NTBI & $<1 \mathrm{~m}-6 \mathrm{~m}$ & $\begin{array}{l}25 \% \text { decrease in metabolism }(17 \%<3 \mathrm{~m} \text { and } 33 \%> \\
3 \mathrm{~m})\end{array}$ \\
\hline Laureys et al., 1999 [62] & 1 & VS/UWS & NTBI & $1 \mathrm{~m}$ & $\begin{array}{l}38 \% \text { decrease in metabolism; recovery of consciousness } \\
=\text { FP recovery }\end{array}$ \\
\hline Laureys et al., 1999 [61] & 4 & VS/UWS & TBI/ NTBI & $<1 \mathrm{~m}-60 \mathrm{~m}$ & FP hypometabolism \& disconnections \\
\hline Laureys et al., 2000 [59] & 1 & VS/UWS & NTBI & $4 \mathrm{~m}$ & $\begin{array}{l}\text { recovery of consciousness }=\text { thalamocortical reconnec- } \\
\text { tions }\end{array}$ \\
\hline Rudolf et al., 2000 [87] & 9 & VS/UWS & NTBI & $<1 \mathrm{~m}$ & decrease in benzodiazepine receptor density \\
\hline Laureys et al., 2002 [50] & 30 & VS/UWS & TBI/ NTBI & $1-5 \mathrm{~m}$ & $56 \%(37-72 \%)$ decrease in metabolism \\
\hline Beuthien-Baumann, 2003 [10] & 16 & VS/UWS & TBI & $2-12 \mathrm{~m}$ & $58 \%$ decrease in metabolism; FP hypometabolism \\
\hline Tengvar, 2004 [101] & 1 & MCS & NTBI & $6 \mathrm{~m}$ & 47-65\% FP hypometabolism \\
\hline Juengling et al., 2005 [44] & 5 & VS/UWS & NTBI & $1-48 \mathrm{~m}$ & FP and thalamus hypometabolism \\
\hline Nakayama et al., 2006 [75] & 30 & $\begin{array}{l}17 \mathrm{VS} / \mathrm{UWS} \\
13 \mathrm{MCS}\end{array}$ & TBI & $6-60 \mathrm{~m}$ & $\begin{array}{l}\text { FP and thalamus hypometabolism in VS/UWS, less } \\
\text { impaired in MCS }\end{array}$ \\
\hline Silva et al., 2010 [98] & 10 & VS/UWS & TBI/ NTBI & $2-24 \mathrm{~m}$ & FP hypometabolism \\
\hline Lull et al., 2010 [68] & 17 & $\begin{array}{l}\text { VS/UWS } \\
\& \text { MCS }\end{array}$ & TBI & $12 \mathrm{~m}$ & thalamus hypometabolism \\
\hline Bruno et al., 2010 [20] & 10 & VS/UWS & NTBI & $3 \mathrm{~m}$ & $\begin{array}{l}\text { FP hypometabolism (VS/UWS without fixation = } \\
\text { "MCS" with fixation) }\end{array}$ \\
\hline \multicolumn{6}{|l|}{ B. $f M R I$} \\
\hline Boly et al., 2009 [16] & 1 & VS/UWS & NTBI & $36 \mathrm{~m}$ & FP disconnections \\
\hline Cauda et al., 2009 [22] & 3 & VS/UWS & TBI/NTBI & $20 \mathrm{~m}$ & FP disconnections \\
\hline Vanhaudenhuyse et al., 2009 [108] & 13 & $\begin{array}{l}4 \mathrm{VS} / \mathrm{UWS} \\
\& 5 \text { coma } \\
4 \mathrm{MCS}\end{array}$ & TBI/NTBI & $<1-60 \mathrm{~m}$ & FP disconnections correlate with consciousness level \\
\hline
\end{tabular}

Note. $\mathrm{N}=$ Number of patients; VS/UWS = vegetative state/unresponsive wakefulness syndrome; MCS = minimally conscious state; FP = frontoparietal associative network; TBI $=$ traumatic brain injury; NTBI $=$ non traumatic brain injury; $\mathrm{m}=\mathrm{months}$.

Functional connectivity PET studies (acquired at rest and during external auditory and somatosensory stimulation) made us propose to consider VS/UWS as a cortico-cortical $[57,60,61]$ and thalamo-cortical $[58$, 59] disconnection syndrome. The study of VS/UWS patients who subsequently recovered offered an additional causal link between consciousness and the functional integrity of this frontoparietal network and its long-range cortico-thalamo-cortical connectivity - especially its non-specific (central intralaminar) thalamic projections [59]. The critical role of these diffusely projecting thalamic nuclei in consciousness was corroborated by Schiff et al. [89] deep-brain stimulation study in MCS.

Only recently it became possible to measure "resting state" brain activity by means of non-ionizing functional MRI (fMRI). In contrast to FDG-PET where one image is obtained representing the average metabolic activity of approximately 30 minutes, fMRI resting state acquisitions offer a series of scans (i.e., a time series) classically obtained during about $10 \mathrm{~min}$ utes representing a more indirect measurement of neu- ral function (i.e., assessing hemodynamic changes). These fMRI data obtained at "rest" (that is without any stimulation in contrast to classical fMRI activation studies discussed below) permit to extract (using a multitude of novel and methodologically complicated preprocessing and analyses tools) [99] the socalled "default mode network" activity [15]. This "default mode network", encompassing midline cortices (i.e., anterior cingulate/mesiofrontal and posterior cingulate/precuneus) is thought to reflect internal or selfawareness (i.e., spontaneous thoughts, inner speech and mind wandering) $[64,99,106]$. Resting state fMRI studies have shown that this network disappears in brain death [16] and decreases in VS/UWS [16,22,108] (Table 2B). MCS patients showed an intermediate pattern with a higher functional connectivity of the posterior cingulate/precuneus area as compared to unresponsive patients [108] - confirming the above-discussed FDGPET results. Interestingly, the authors also showed a linear correlation between behavioral CRS-R total scores and "default mode network" connectivity. 


\section{5. “Activation" studies using sensory stimulation}

In the late 1990s functional neuroimaging activation studies used ${ }^{15} \mathrm{O}$ labeled water PET measuring regional increases in cerebral blood flow in response to passive external (auditory, somatosensory or visual) stimulation. Table 3A summarizes these studies, showing that for most VS/UWS patients a "low level" cortical activation was reported encompassing primary auditory $[13,57,78,90]$, somatosensory $[14,60]$ or visual $[37$, 72] cortices. These results showed that sensory stimulation in VS/UWS induced not only subcortical neural activation but also robustly activated gray matter regions [45]. Functional connectivity studies, however, showed that these cortical activations existed like an island isolated from the frontoparietal network discussed above, thought to be necessary for the emergence of conscious perception [11].

The preservation of isolated "low-level" cortical activation to passive sensory stimulation has lately been corroborated by fMRI [9,26,34,41,84] (Table 3B). Moreover, these studies are also showing the potential prognostic value of the technique [25,31]. Indeed, VS/UWS with absent or low-level brain activation (i.e., the majority of the studied cases) have lower chances of subsequent recovery as compared to those with higherlevel activation (i.e., activation extending to associative multimodal cortices). The latter pattern of activation is often (albeit not always) encountered in MCS patients [113]. Connectivity studies showed not only a higher level of functional segregation (i.e., more widespread activation) in MCS but also of functional integration (i.e., more functional long range corticocortical connectivity with the frontoparietal "awareness" network) as compared to VS/UWS for both auditory [13] and noxious processing [14]. The latter study, showing good evidence of residual pain perception in MCS has obvious clinical consequences.

As for consciousness, pain is a first person subjective experience that cannot be reduced to activity in a single brain region but involves the so-called "pain matrix" [97]. The observed activation of the whole of the pain matrix in MCS [14], including the anterior cingulate and insular areas thought to be important in the affective emotional perception of pain [47] should prompt physicians to systematically use pain killers in MCS, even if (by definition) they cannot communicate their sensations [30]. A recently proposed "pain scale" specifically developed for use in DOC now permits to monitor and adapt the level of nociception/pain and analgesia treatment [92]. This Nociception Coma Scale proposes that when the total score (based on assessment of motor, verbal, visual and facial responses) is above 7 out of 12, treatment should be started or continued.

Functional neuroimaging studies have also aimed to address the question whether DOC patients perceive emotions. A series of studies have illustrated that intense or emotionally relevant stimuli induce higher-level activation in MCS (for review [52]). In the auditory modality, these studies have used presentation of meaningful stories told by a relative [7,91] or auto-referential stimuli such as the patient's own name $[32,65,81]$. The latter studies, for example, show activation of midline structures (i.e., anterior cingulate/mesiofrontal and posterior cingulate/precuneus) [65,81] known to be involved in self-consciousness [64]. However, it should again be stressed that activation of a brain area (or network) per se does not consist an absolute proof of consciousness but could be considered as "automatic" processing.

\section{Proving consciousness without movement}

In addition to the above reviewed "resting state" and "passive stimulation" functional neuroimaging studies, recent fMRI paradigms aimed at showing proof of command following in the scanner. Mental imagery tasks (such as imagine playing tennis) will activate specific brain areas (premotor cortex for motor imagery) that can easily be picked-up by block-design fMRI [12]. When a behaviorally unresponsive patient repeatedly shows robust activation of premotor cortex if and only if she or he is requested to do the mental imagery task, this constitutes objective evidence that the patient understood and obeyed the command and hence must be conscious. In 2006, this approach first illustrated its potential to show fMRI signs of consciousness unavailable to clinical assessment [76]. The technique was soon adapted to electroencephalography based event related potential (ERP) paradigms and have since proven their utility in clinical routine. In this ERP version of the "imaging playing tennis" fMRI approach, patients were asked to "count a name" leading to a P3 wave on the EEG recording. In the reported series, $21 \%(3 / 14)$ of patients showed ERP proof of command following impossible to demonstrate during repeated behavioral assessments [95]. The technique also permitted to identify a case of complete locked-in syndrome [94]. Similar ERP [6] and electromyographic (EMG) [8] techniques have since been developed showing respectively 20 or $17 \%$ of DOC patients demonstrating voluntary 
Table 3

Brain activation's level in response to passive sensory stimulation as measured by (A) ${ }^{15} \mathrm{O}$ labeled water PET and (B) fMRI in disorders of consciousness

\begin{tabular}{|c|c|c|c|c|c|c|}
\hline References & Etiology & Duration & $\mathrm{N}$ & Diagnostic & Modality & $\begin{array}{l}\text { Level of } \\
\text { activation }\end{array}$ \\
\hline \multicolumn{7}{|l|}{ A. PET } \\
\hline De Jong et al., 1997 [27] & TBI & $2 \mathrm{~m}$ & 1 & VS/UWS & auditory (familiar voice) & high \\
\hline Menon et al., 1998 [72] & NTBI & $3 \mathrm{~m}$ & 1 & VS/UWS & visual (familiar face) & low \\
\hline Schiff et al., 2002 [90] & TBI/NTBI & $6-300 \mathrm{~m}$ & 5 & $\begin{array}{l}3 \mathrm{VS} / \mathrm{UWS} \\
2 \mathrm{VS} / \mathrm{UWS}\end{array}$ & auditory (click), tactile & $\begin{array}{l}\text { low } \\
\text { high }\end{array}$ \\
\hline Owen et al., 2002 [78] & TBI/NTBI & $4 \mathrm{~m}$ & 3 & $\begin{array}{l}1 \mathrm{VS} / \mathrm{UWS} \\
2 \mathrm{VS} / \mathrm{UWS}\end{array}$ & visual (familiar face), auditory (noise, words) & $\begin{array}{l}\text { low } \\
\text { high }\end{array}$ \\
\hline Laureys et al., 2002 [60] & TBI/NTBI & $1 \mathrm{~m}$ & 15 & VS/UWS & pain (electrical stimulation) & low \\
\hline Kassubek et al., 2003 [45] & NTBI & $3-48 \mathrm{~m}$ & 7 & VS/UWS & pain (electrical stimulation) & high \\
\hline Boly et al., 2004 [13] & TBI/NTBI & $1-4 \mathrm{~m}$ & 20 & $\begin{array}{l}15 \mathrm{VS} / \mathrm{UWS} \\
5 \mathrm{MCS}\end{array}$ & auditory (click) & $\begin{array}{l}\text { low } \\
\text { high }\end{array}$ \\
\hline Laureys et al., 2004 [65] & NTBI & $6 \mathrm{~m}$ & 1 & MCS & auditory (noise, cries, own name) & high \\
\hline Owen et al., 2005 [77] & NTBI & $4 \mathrm{~m}$ & 1 & VS/UWS & auditory (speech) & high \\
\hline Giacino et al., 2006 [37] & TBI/NTBI & $1-3 \mathrm{~m}$ & 5 & VS/UWS & visual (flash) & low \\
\hline Boly et al., 2008 [14] & & $1-4 \mathrm{~m}$ & $\begin{array}{c}15 \\
5\end{array}$ & $\begin{array}{l}\text { VS/UWS } \\
\text { MCS }\end{array}$ & pain (electrical stimulation) & $\begin{array}{l}\text { low } \\
\text { high }\end{array}$ \\
\hline Silva et al., 2010 [98] & TBI/NTBI & $2-22 \mathrm{~m}$ & 10 & VS/UWS & tactile & low \\
\hline \multicolumn{7}{|l|}{ B. $f M R I$} \\
\hline Moritz et al., 2001 [74] & TBI & $<1 \mathrm{~m}$ & 1 & VS/UWS & tactile, visual (flash), auditory (speech) & high \\
\hline Bekinschtein et al., 2004 [7] & TBI & $5 \mathrm{~m}$ & 1 & MCS & auditory (familiar voice) & high \\
\hline Bekinschtein et al., 2005 [9] & TBI & $2 \mathrm{~m}$ & 1 & VS/UWS & auditory (words) & low \\
\hline Schiff et al., 2005 [91] & TBI/NTBI & $18 \mathrm{~m}$ & 2 & MCS & auditory (speech), tactile & high \\
\hline Owen et al., 2006 [76] & TBI & $6 \mathrm{~m}$ & 1 & VS/UWS & auditory (speech, ambiguity), visual & high \\
\hline Staffen et al., 2006 [100] & NTBI & $10 \mathrm{~m}$ & 1 & VS/UWS & auditory (own name) & high \\
\hline Di et al., 2007 [32] & TBI/NTBI & $2-48 \mathrm{~m}$ & 11 & $\begin{array}{l}5 \mathrm{VS} / \mathrm{UWS} \\
2 \mathrm{VS} / \mathrm{UWS} \\
4 \mathrm{MCS}\end{array}$ & auditory (familiar voice own name ) & $\begin{array}{l}\text { low } \\
\text { high } \\
\text { high }\end{array}$ \\
\hline Coleman et al., 2007 [26] & TBI/NTBI & 9-108 m & 12 & $4 \mathrm{VS} / \mathrm{UWS}$ & $\begin{array}{l}\text { auditory (forward/backward speech, ambig- } \\
\text { uity) }\end{array}$ & low \\
\hline & & & & $\begin{array}{l}3 \mathrm{VS} / \mathrm{UWS} \\
5 \mathrm{MCS}\end{array}$ & & $\begin{array}{l}\text { high } \\
\text { low/high }\end{array}$ \\
\hline Fernandez-Espejo et al., 2008 [34] & TBI & $1-11 \mathrm{~m}$ & 7 & $\begin{array}{l}2 \mathrm{VS} / \mathrm{UWS} \\
1 \mathrm{VS} / \mathrm{UWS} \\
4 \mathrm{MCS}\end{array}$ & auditory (forward/backward speech) & $\begin{array}{l}\text { low } \\
\text { high } \\
\text { low/high }\end{array}$ \\
\hline Rousseau et al., 2008 [84] & NTBI & $60 \mathrm{~m}$ & 4 & VS & tactile, visual and auditory & low \\
\hline Coleman et al., 2009 [25] & TBI/NTBI & $2-120 \mathrm{~m}$ & 46 & $\begin{array}{l}20 \mathrm{VS} / \mathrm{UWS} \\
7 \mathrm{VS} / \mathrm{UWS} \\
19 \mathrm{MCS}\end{array}$ & $\begin{array}{l}\text { auditory (forward/backward speech, ambi- } \\
\text { guity) }\end{array}$ & $\begin{array}{l}\text { low } \\
\text { high } \\
\text { low/high }\end{array}$ \\
\hline Zhu et al., 2009 [113] & TBI/NTBI & $1-2 \mathrm{~m}$ & 9 & MCS & visual (emotional picture) & high \\
\hline Qin et al., 2010 [81] & TBI/NTBI & $2-48 \mathrm{~m}$ & 11 & $\begin{array}{l}7 \mathrm{VS} / \mathrm{UWS} \\
4 \mathrm{MCS}\end{array}$ & auditory (familiar voice own name) & $\begin{array}{l}\text { low } \\
\text { high }\end{array}$ \\
\hline Fernandez-Espejo et al., 2010 [33] & TBI & $1 \mathrm{~m}$ & 1 & VS/UWS & auditory (speech forward/backward) & high \\
\hline Heelman et al., 2010 [41] & TBI & $\begin{array}{l}<2 \mathrm{~m},>6 \mathrm{~m} \\
14 \mathrm{~m}\end{array}$ & 6 & $\begin{array}{l}6 \mathrm{VS} / \mathrm{UWS} \\
1 \mathrm{MCS}\end{array}$ & visual (flash) & $\begin{array}{l}\text { low } \\
\text { high }\end{array}$ \\
\hline
\end{tabular}

Note. $\mathrm{N}=$ Number of patients; VS/UWS = vegetative state/unresponsive wakefulness syndrome; MCS = minimally conscious state; FP = frontoparietal associative network; TBI = traumatic brain injury; NTBI = non traumatic brain injury; $\mathrm{m}=$ months.

response to command inaccessible to clinical bedside examination.

A multicentric fMRI study enrolling 54 patients in Cambridge and Liège similarly showed that in $17 \%$ of the cases command following was documented based on neural activity measurements, in the absence of behavioral command following [73]. It should be stressed that these techniques suffer from a low sensitivity (3\%), meaning that negative results cannot lead to strong con- clusions as many (minimally) conscious brain damaged patients will fail to show command-related fMRI activation. Most interestingly, however, the study showed that fMRI can be used as a way to communicate via yes/no questions. Obviously, EEG based alternatives, called brain computer interfaces or BCIs, that are transportable, cheaper and less sensitive to involuntary movements should now be tested in DOC patients. In our view, the medical community, together with ethi- 
Table 4

Current World Health Organization's International Classification of Diseases 2011 ICD-9-CM codes for disorders of consciousness and locked-in syndrome

\begin{tabular}{|c|c|c|}
\hline Diagnosis Code & Diagnosis & Definition \\
\hline 780.0 & Alteration of consciousness & None \\
\hline-780.01 & Coma & $\begin{array}{l}\text { Profound state of unconsciousness associated with depressed cerebral activity } \\
\text { from which the individual cannot be aroused; coma generally occurs when there } \\
\text { is dysfunction or injury involving both cerebral hemispheres or the brain stem. }\end{array}$ \\
\hline-780.02 & Transient alteration of awareness & None \\
\hline-780.03 & Persistent vegetative state & None \\
\hline-780.09 & Alteration of consciousness other & $\begin{array}{l}\text { - Loss of the ability to maintain awareness of self and environment combined } \\
\text { with markedly reduced responsiveness to environmental stimuli. } \\
\text { - The neurologic status characterized by the occurrence of a loss of the ability to } \\
\text { perceive and respond. } \\
\text { - Obtundation, a dulled or reduced level of alertness or consciousness. }\end{array}$ \\
\hline 344.8 & Other specified paralytic syndromes & \\
\hline-344.81 & Locked-in state & None \\
\hline
\end{tabular}

Table 5

MEDLINE MeSH Categories for "disorders of consciousness".

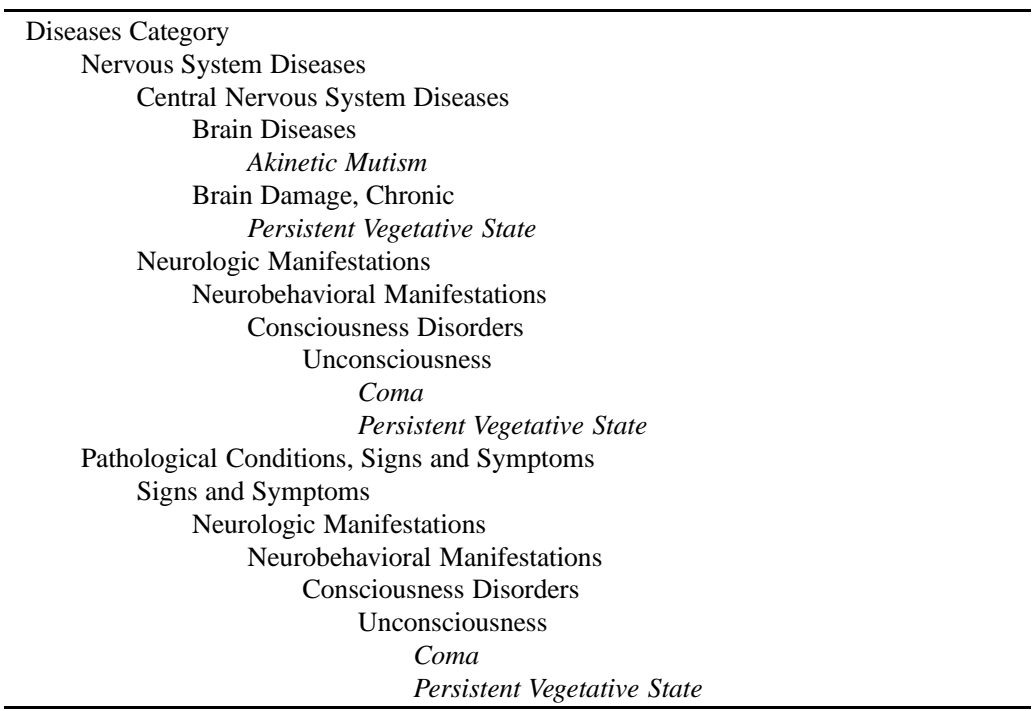

cal and legal scholars [35], needs to prepare the future clinical use and guidelines defining how to make the best possible use of these assisted communication technology in the context of DOC. After we defined when to trust the measurements, we need to define when to consider the patient as competent and capable to express her/his quality of life and to exercise the right of self-determination.

\section{Remaining challenges, appropriate indexing and future developments}

It is clear that our understanding of consciousness and disorders of consciousness after coma is currently witnessing a paradigm shift, especially thanks to the re- sults obtained in functional neuroimaging $[51,79]$. The challenge now is to move from single case reports and small cohort reports to large multi-centric studies further addressing the sensitivity and specificity of the discussed "high-tech" para-clinical neuroimaging or electrophysiological tools. In order to propose validated evidence based algorithms specifying when and what investigation needs to be performed in which patient for diagnostic or prognostic purposes, much more research efforts and funding are required. Many of the listed studies were published prior to the formal recognition of the diagnostic criteria of MCS [36], it can hence not be formally excluded that some of these patients might have been minimally conscious. In part of the listed papers, the clinical distinction between, VS/UWS from MCS is suboptimal. 
Unfortunately, the World Health Organization does not yet recognize the minimally conscious state in its International Statistical Classification of Diseases (9th Revision, Clinical Modification; ICD-9-CM) diagnosis codes and related Current Procedural Terminology (CPT) medical procedure codes (maintained by the American Medical Association). ICD codes classify symptoms, diseases, or injuries into categories with unique codes permitting standardized epidemiological, morbidity and mortality studies, reimbursement and medical decision-making. The lack of a unique code for MCS hinders comparison with VS/UWS prevalence and prognosis and international statistics (Table 4). We have therefore proposed a 2011 ICD-9-CM Diagnosis Code 780.04 for the minimally conscious state, defined as "non-communicative wakeful patients with inconsistent but clearly discernible behavioral evidence of consciousness to be distinguished from comatose, vegetative or unresponsive patients by the presence of nonreflex movements (e.g., eye-tracking or orientation to pain) or command following".

Likewise, MEDLINE (i.e., Medical Literature Analysis and Retrieval System Online compiled by the United States National Library of Medicine and National Institutes of Health) does not offer a MeSH term (i.e., Medical Subject Heading permitting controlled vocabulary for indexing and database searches) for MCS. At present "MCS" is an entry term included in the MeSH term "Persistent Vegetative State" (introduced in 1995, previously indexed under "Coma"). Note that also locked-in syndrome is not a MeSH entry term whereas MEDLINE indexed "Akinetic Mutism" in 1971 (Table 5).

Undoubtedly, it is an exciting era for the field of brain injury and disorders of consciousness. The gray zones between the different clinical entities in the spectrum following coma are beginning to be better understood and defined by the increasingly powerful neuroimaging technology. As we have here briefly discussed a yet to be determined minority of patients who are currently considered to be "vegetative" or unresponsive, show fMRI or ERP based signs of consciousness that are inaccessible to clinicians' motor-response dependent behavioral assessment. These ever improving technological means are changing the existing clinical boundaries and will permit some "non-communicative" and locked-in $[19,40,63]$ patients to correspond their thoughts and wishes and control their environment via non-motor pathways. In our view, it would be highly preferable to soon have a separate ICD-9-CM Diagnosis Code and MeSH entry for MCS as the lack of clear distinction between VS/UWS and MCS may encumber scientific studies, medical information retrieval, demographic and international analyses in the rapidly changing and challenging field of disorders of consciousness.

\section{Acknowledgements}

This study was supported by the Fonds de la Recherche Scientifique (FNRS), James S. McDonnell Foundation, Mind Science Foundation, European Commission (Mindbridge, DISCOS, DECODER \& COST) and Concerted Research Action (ARC 06/11-340). OG, MAB and CC are Research Fellow at FNRS. AV and CS are Postdoctoral Fellows at FNRS. SL is Senior Research Associate at FNRS.

\section{References}

[1] American Congress of Rehabilitation Medicine, Recommendations for use of uniform nomenclature pertinent to patients with severe alterations of consciousness, Arch Phys Med Rehabil 76 (1995), 205-209.

[2] American Congress of Rehabilitation Medicine, Brain Injury-Interdisciplinary Special Interest Group, Disorders of Consciousness Task Force, R. Seel, M. Sherer, J. Whyte, D. Katz, J. Giacino, A. Rosenbaum, F. Hammond, K. Kalmar, T. Pape, R. Zafonte, R. Biester, D. Kaelin, J. Kean and N. Zasler, Assessment scales for disorders of consciousness: evidencebased recommendations for clinical practice and research, Arch Phys Med Rehabil 91(12) (2010), 795-813.

[3] K. Andrews, L. Murphy, R. Munday and C. Littlewood, Misdiagnosis of the vegetative state: retrospective study in a rehabilitation unit, BMJ 313(7048) (1996), 13-16.

[4] Australian Government National Health and Medical Research Council, Post-Coma Unresponsiveness (Vegetative State): A Clinical Framework for Diagnosis. An information Paper, 2003.

[5] B.J. Baars, T.Z. Ramsoy and S. Laureys, Brain, conscious experience and the observing self, Trends Neurosci 26(12) (2003), 671-675.

[6] T. Bekinschtein, S. Dehaene, B. Rohaut, F. Tadel, L. Cohen and N.L., Neural signature of the conscious processing of auditory regularities, Proc Natl Acad Sci US A 106(5) (2009), 1672-1677.

[7] T. Bekinschtein, R. Leiguarda, J. Armony, A. Owen, S. Carpintiero, J. Niklison, L. Olmos, L. Sigman and F. Manes, Emotion processing in the minimally conscious state, $\mathrm{J} \mathrm{Neu}$ rol Neurosurg Psychiatry 75(5) (2004), 788.

[8] T. Bekinschtein, D. Shalom, C. Forcato, M. Herrera, M. Coleman, F. Manes and M. Sigman, Classical conditioning in the vegetative and minimally conscious state, Nat Neurosci 12(10) (2009), 1343-1349.

[9] T. Bekinschtein, C. Tiberti, J. Niklison, M. Tamashiro, M. Ron, S. Carpintiero, M. Villarreal, C. Forcato, R. Leiguarda and F. Manes, Assessing level of consciousness and cognitive changes from vegetative state to full recovery, Neuropsychol Rehabil 15(3-4) (2005), 307-322. 
[10] B. Beuthien-Baumann, W. Handrick, T. Schmidt, W. Burchert, L. Oehme, J. Kropp, G. Schackert, J. Pinkert and W.G. Franke, Persistent vegetative state: evaluation of brain metabolism and brain perfusion with PET and SPECT, $\mathrm{Nucl}$ Med Commun 24(6) (2003), 643-649.

[11] M. Boly, E. Balteau, C. Schnakers, C. Degueldre, G. Moonen, A. Luxen, C. Phillips, P. Peigneux, P. Maquet and S. Laureys, Baseline brain activity fluctuations predict somatosensory perception in humans, Proc Natl Acad Sci U S A 104(29) (2007), 12187-12192.

[12] M. Boly, M.R. Coleman, M.H. Davis, A. Hampshire, D. Bor, G. Moonen, P.A. Maquet, J.D. Pickard, S. Laureys and A.M. Owen, When thoughts become action: an fMRI paradigm to study volitional brain activity in non-communicative brain injured patients, Neuroimage 36(3) (2007), 979-992.

[13] M. Boly, M.E. Faymonville, P. Peigneux, B. Lambermont, P. Damas, G. Del Fiore, C. Degueldre, G. Franck, A. Luxen, M. Lamy, G. Moonen, P. Maquet and S. Laureys, Auditory processing in severely brain injured patients: differences between the minimally conscious state and the persistent vegetative state, Arch Neurol 61(2) (2004), 233-238.

[14] M. Boly, M.E. Faymonville, C. Schnakers, P. Peigneux, B. Lambermont, C. Phillips, P. Lancellotti, A. Luxen, M. Lamy, G. Moonen, P. Maquet and S. Laureys, Perception of pain in the minimally conscious state with PET activation: an observational study, Lancet Neurol 7(11) (2008), 1013-1020.

[15] M. Boly, C. Phillips, E. Balteau, C. Schnakers, C. Degueldre, G. Moonen, A. Luxen, P. Peigneux, M.E. Faymonville, P. Maquet and S. Laureys, Consciousness and cerebral baseline activity fluctuations, Hum Brain Mapp 29(7) (2008), 868874.

[16] M. Boly, L. Tshibanda, A. Vanhaudenhuyse, Q. Noirhomme, C. Schnakers, D. Ledoux, P. Boveroux, C. Garweg, B. Lambermont, C. Phillips, A. Luxen, G. Moonen, C. Bassetti, P. Maquet and S. Laureys, Functional connectivity in the default network during resting state is preserved in a vegetative but not in a brain dead patient, Hum Brain Mapp 30(8) (2009), 2393-2400.

[17] P. Boveroux, V. Bonhomme, M. Boly, A. Vanhaudenhuyse, P. Maquet and S. Laureys, Brain function in physiologically, pharmacologically, and pathologically altered states of consciousness, Int Anesthesiol Clin 46(3) (2008), 131-146.

[18] M.A. Bruno, D. Fernández-Espejo, R. Lehembre, L. Tshibanda, A. Vanhaudenhuyse, O. Gosseries, E. Lommers, Q. Noirhomme, M. Boly, M. Napolitani, A. Owen, S. Laureys and A. Soddu, Multi-modal neuroimaging in patients with disorders of consciousness showing functional hemispherectomy, Progress in Brain Research, in press.

[19] M.A. Bruno, C. Schnakers, F. Damas, F. Pellas, I. Lutte, J. Bernheim, S. Majerus, G. Moonen, S. Goldman and S. Laureys, Locked-in syndrome in children: report of five cases and review of the literature, Pediatr Neurol 41(4) (2009), 237-246.

[20] M.A. Bruno, A. Vanhaudenhuyse, C. Schnakers, M. Boly, O. Gosseries, A. Demertzi, S. Majerus, G. Moonen, R. Hustinx and S. Laureys, Visual fixation in the vegetative state: an observational case series PET study, BMC Neurol 10(1) (2010), 35 .

[21] J. Calvet and J. Coll, Meningitis of sinusoid origin with the form of coma vigil, Rev Otoneuroophtalmol 31 (1959), 443445.

[22] F. Cauda, B. Micon, K. Sacco, S. Duca, F. D’Agata, G. Geminiani and S. Canavero, Disrupted intrinsic functional con- nectivity in the vegetative state, $J$ Neurol Neurosurg Psychiatry 80(4) (2009), 429-431.

[23] G. Celesia, Persistent vegetative state: clinical and ethical issues, Suppl Clin Neurophysiol 53 (2000), 460-462.

[24] N.L. Childs and W.N. Mercer, Misdiagnosing the persistent vegetative state. Misdiagnosis certainly occurs [letter; comment], BMJ 313(7062) (1996), 944.

[25] M. Coleman, M. Davis, J. Rodd, T. Robson, A. Ali, A. Owen and J. Pickard, Towards the routine use of brain imaging to aid the clinical diagnosis of disorders of consciousness, Brain 132(Pt 9) (2009), 2541-2552.

[26] M. Coleman, J.M. Rodd, M.H. Davis, I.S. Johnsrude, D.K. Menon, J.D. Pickard and A.M. Owen, Do vegetative patients retain aspects of language comprehension? Evidence from fMRI, Brain 130(10) (2007), 2494-2507.

[27] B. de Jong, A.T. Willemsen and A.M. Paans, Regional cerebral blood flow changes related to affective speech presentation in persistent vegetative state, Clin Neurol Neurosurg 99(3) (1997), 213-216.

[28] A.G. De Volder, A.M. Goffinet, A. Bol, C. Michel, B.T. de and C. Laterre, Brain glucose metabolism in postanoxic syndrome. Positron emission tomographic study, Arch Neurol 47(2) (1990), 197-204.

[29] S. Dehaene, The Cognitive Neuroscience of Consciousness, Cambridge, MA, MIT Press, 2000.

[30] A. Demertzi, C. Schnakers, D. Ledoux, C. Chatelle, M.A. Bruno, A. Vanhaudenhuyse, M. Boly, G. Moonen and S. Laureys, Different beliefs about pain perception in the vegetative and minimally conscious states: a European survey of medical and paramedical professionals, Prog Brain Res 177 (2009), 329-338.

[31] H. Di, M. Boly, X. Weng, D. Ledoux and S. Laureys, Neuroimaging activation studies in the vegetative state: predictors of recovery? Clin Med 8(5) (2008), 502-507.

[32] H. Di, S.M. Yu, X.C. Weng, S. Laureys, D. Yu, J.Q. Li, P.M. Qin, Y.H. Zhu, S.Z. Zhang and Y.Z. Chen, Cerebral response to patient's own name in the vegetative and minimally conscious states, Neurology 68(12) (2007), 895-899.

[33] D. Fernandez-Espejo, C. Junque, D. Cruse, M. Bernabeu, T. Roig-Rovira, N. Fábregas, E. Rivas and J. Mercader, Combination of diffusion tensor and functional magnetic resonance imaging during recovery from the vegetative state, $\mathrm{BMCNeu}$ rol 10 (2010), 77.

[34] D. Fernandez-Espejo, C. Junque, P. Vendrell, M. Bernabeu, T. Roig, N. Bargallo and J.M. Mercader, Cerebral response to speech in vegetative and minimally conscious states after traumatic brain injury, Brain Inj 22(11) (2008), 882-890.

[35] J. Fins, J. Illes, J. Bernat, J. Hirsch, S. Laureys and E. Murphy, Neuroimaging and disorders of consciousness: envisioning an ethical research agenda, Am J Bioeth 8(9) (2008), 3-12.

[36] J.T. Giacino, S. Ashwal, N. Childs, R. Cranford, B. Jennett, D.I. Katz, J.P. Kelly, J.H. Rosenberg, J. Whyte, R.D. Zafonte and N.D. Zasler, The minimally conscious state: Definition and diagnostic criteria, Neurology 58(3) (2002), 349-353.

[37] J.T. Giacino, J. Hirsch, N. Schiff and L.S., Functional neuroimaging applications for assessment and rehabilitation planning in patients with disorders of consciousness, Arch Phys Med Rehabil 87(Suppl 2) (2006), 67-76.

[38] J.T. Giacino, K. Kalmar and J. Whyte, The JFK Coma Recovery Scale-Revised: measurement characteristics and diagnostic utility, Arch Phys Med Rehabil 85(12) (2004), 20202029.

[39] H. Gill-Thwaites and R. Munday, The sensory modality assessment and rehabilitation technique (SMART): a valid and 
reliable assessment for vegetative state and minimally conscious state patients, Brain Inj 18(12) (2004), 1255-1269.

[40] O. Gosseries, M.A. Bruno, A. Vanhaudenhuyse, S. Laureys and C. Schnakers, Consciousness in the Locked-in Syndrome, in: The Neurology of Consciousness: Cognitive Neuroscience and Neuropathology, S. Laureys and G. Tononi, eds, Oxford, Elsevier, 2009, pp. 191-203.

[41] V. Heelmann, M. Lippert-Grüner, T. Rommel and C. Wedekind, Abnormal functional MRI BOLD contrast in the vegetative state after severe traumatic brain injury, Int $J$ Rehabil Res 33(2) (2010), 151-157.

[42] B. Jennett, The vegetative state. Medical facts, ethical and legal dilemmas. Cambridge, Cambridge University Press, 2002.

[43] B. Jennett and F. Plum, Persistent vegetative state after brain damage. A syndrome in search of a name, Lancet 1(7753) (1972), 734-737.

[44] F.D. Juengling, J. Kassubek, H.J. Huppertz, T. Krause and T. Els, Separating functional and structural damage in persistent vegetative state using combined voxel-based analysis of 3-D MRI and FDG-PET, J Neurol Sci 228(2) (2005), 179-184.

[45] J. Kassubek, F.D. Juengling, T. Els, J. Spreer, M. Herpers, T. Krause, E. Moser and C.H. Lucking, Activation of a residual cortical network during painful stimulation in long-term postanoxic vegetative state: a 15O-H2O PET study, J Neurol Sci 212(1-2) (2003), 85-91.

[46] E. Kretschmer, Das apallische Syndrom, Z ges Neurol Psychiat 169 (1940), 576-579.

[47] R. Kupers, M.E. Faymonville and S. Laureys, The cognitive modulation of pain: hypnosis- and placebo-induced analgesia, Prog Brain Res 150 (2005), 251-269.

[48] S. Laureys, The neural correlate of (un)awareness: lessons from the vegetative state, Trends Cogn Sci 9(12) (2005), 556559.

[49] S. Laureys, Permanent vegetative state and persistent vegetative state are not interchangeable terms, [http://bmj.com/cgi/eletters/321/7266/916\#10276]. British Medical Journal 2000.

[50] S. Laureys, S. Antoine, M. Boly, S. Elincx, M.E. Faymonville, J. Berre, B. Sadzot, M. Ferring, X. De Tiege, P. van Bogaert, I. Hansen, P. Damas, N. Mavroudakis, B. Lambermont, G. Del Fiore, J. Aerts, C. Degueldre, C. Phillips, G. Franck, J.L. Vincent, M. Lamy, A. Luxen, G. Moonen, S. Goldman and P. Maquet, Brain function in the vegetative state, Acta Neurol Belg 102(4) (2002), 177-185.

[51] S. Laureys and M. Boly, The changing spectrum of coma, Nat Clin Pract Neurol 4(10) (2008), 544-546.

[52] S. Laureys and M. Boly, What is it like to be vegetative or minimally conscious? Curr Opin Neurol 20(6) (2007), 609-613.

[53] S. Laureys, M. Boly and P. Maquet, Tracking the recovery of consciousness from coma, J Clin Invest 116(7) (2006), 1823-1825.

[54] S. Laureys, M. Boly and G. Tononi, Functional Neuroimaging, in: The Neurology of Consciousness: Cognitive Neuroscience and Neuropathology, S. Laureys and G. Tononi, eds, New York, Elsevier, 2009, pp. 30-42.

[55] S. Laureys, G. Celesia, F. Cohadon, J. Lavrijsen, J. LeónCarrión, W. Sannita, L. Sazbon, E. Schmutzhard, K. von Wild, A. Zeman, G. Dolce and t.E.T.F.o.D.o. Consciousness, Unresponsive wakefulness syndrome: a new name for the vegetative state or apallic syndrome, BMC Med 8(1) (2010), 68.
[56] S. Laureys, M.E. Faymonville, X. De Tiege, P. Peigneux, J. Berre, G. Moonen, S. Goldman and P. Maque, Brain function in the vegetative state, Adv Exp Med Biol 550 (2004), 229238.

[57] S. Laureys, M.E. Faymonville, C. Degueldre, G.D. Fiore, P. Damas, B. Lambermont, N. Janssens, J. Aerts, G. Franck, A. Luxen, G. Moonen, M. Lamy and P. Maquet, Auditory processing in the vegetative state, Brain 123(Pt 8) (2000), 1589-1601.

[58] S. Laureys, M.E. Faymonville, S. Goldman, C. Degueldre, C. Phillips, B. Lambermont, J. Aerts, M. Lamy, A. Luxen, G. Franck and P. Maquet, Impaired cerebral connectivity in vegetative state, in: Physiological Imaging of the Brain with PET, A. Gjedde, S.B. Hansen, G.M. Knudsen and O.B. Paulson, eds, San Diego, Academic Press, 2000, pp. 329334.

[59] S. Laureys, M.E. Faymonville, A. Luxen, M. Lamy, G. Franck and P. Maquet, Restoration of thalamocortical connectivity after recovery from persistent vegetative state, Lancet 355(9217) (2000), 1790-1791.

[60] S. Laureys, M.E. Faymonville, P. Peigneux, P. Damas, B. Lambermont, G. Del Fiore, C. Degueldre, J. Aerts, A. Luxen, G. Franck, M. Lamy, G. Moonen and P. Maquet, Cortical processing of noxious somatosensory stimuli in the persistent vegetative state, Neuroimage 17(2) (2002), 732-741.

[61] S. Laureys, S. Goldman, C. Phillips, P. Van Bogaert, J. Aerts, A. Luxen, G. Franck and P. Maquet, Impaired effective cortical connectivity in vegetative state: preliminary investigation using PET, Neuroimage 9(4) (1999), 377-382.

[62] S. Laureys, C. Lemaire, P. Maquet, C. Phillips and G. Franck, Cerebral metabolism during vegetative state and after recovery to consciousness, J Neurol Neurosurg Psychiatry 67(1) (1999), 121.

[63] S. Laureys, F. Pellas, P. Van Eeckhout, S. Ghorbel, C. Schnakers, F. Perrin, J. Berre, M.E. Faymonville, K.H. Pantke, F. Damas, M. Lamy, G. Moonen and S. Goldman, The locked-in syndrome: what is it like to be conscious but paralyzed and voiceless? Prog Brain Res 150 (2005), 495-511.

[64] S. Laureys, F. Perrin and S. Bredart, Self-consciousness in non-communicative patients, Conscious Cogn 16(3) (2007), 722-741.

[65] S. Laureys, F. Perrin, M.E. Faymonville, C. Schnakers, M. Boly, V. Bartsch, S. Majerus, G. Moonen and P. Maquet, Cerebral processing in the minimally conscious state, $\mathrm{Neu}$ rology 63(5) (2004), 916-918.

[66] S. Laureys, S. Piret and D. Ledoux, Quantifying consciousness, Lancet Neurol 4(12) (2005), 789-790.

[67] D.E. Levy, J.J. Sidtis, D.A. Rottenberg, J.O. Jarden, S.C. Strother, V. Dhawan, J.Z. Ginos, M.J. Tramo, A.C. Evans and F. Plum, Differences in cerebral blood flow and glucose utilization in vegetative versus locked-in patients, Ann Neurol 22(6) (1987), 673-682.

[68] N. Lull, E. Noé, J. Lull, J. García-Panach, J. Chirivella, J. Ferri, D. López-Aznar, P. Sopena and M. Robles, Voxelbased statistical analysis of thalamic glucose metabolism in traumatic brain injury: relationship with consciousness and cognition, Brain Inj 24(9) (2010), 1098-1107.

[69] S. Majerus, M. Bruno, C. Schnakers, J. Giacino and S. Laureys, The problem of aphasia in the assessment of consciousness in brain-damaged patients, Prog Brain Res 177(49-61) (2009).

[70] S. Majerus, H. Gill-Thwaites, K. Andrews and S. Laureys, Behavioral evaluation of consciousness in severe brain damage, Prog Brain Res 150 (2005), 397-413. 
[71] P. Maquet, Understanding non rapid eye movement sleep through neuroimaging, World J Biol Psychiatry 11(Suppl 1) (2010), 9-15.

[72] D. Menon, A. Owen, E. Williams, P. Minhas, C. Allen, S. Boniface and J. Pickard, Cortical processing in persistent vegetative state. Wolfson Brain Imaging Centre Team, Lancet 352(9123) (1998), 200.

[73] M.M. Monti, A. Vanhaudenhuyse, M.R. Coleman, M. Boly, J.D. Pickard, L. Tshibanda, A.M. Owen and S. Laureys, Willful modulation of brain activity in disorders of consciousness, N Engl J Med 362(7) (2010), 579-589.

[74] C.H. Moritz, H.A. Rowley, V.M. Haughton, K.R. Swartz, J. Jones and B. Badie, Functional MR imaging assessment of a non-responsive brain injured patient, Magn Reson Imaging 19(8) (2001), 1129-1132.

[75] N. Nakayama, A. Okumura, J. Shinoda, T. Nakashima and T. Iwama, Relationship between regional cerebral metabolism and consciousness disturbance in traumatic diffuse brain injury without large focal lesions: an FDG-PET study with statistical parametric mapping analysis, J Neurol Neurosurg Psychiatry 77(7) (2006), 856-862.

[76] A.M. Owen, M.R. Coleman, M. Boly, M.H. Davis, S. Laureys and J.D. Pickard, Detecting awareness in the vegetative state, Science 313(5792) (2006), 1402.

[77] A.M. Owen, M.R. Coleman, D.K. Menon, I.S. Johnsrude, J.M. Rodd, M.H. Davis, K. Taylor and J.D. Pickard, Residual auditory function in persistent vegetative state: a combined pet and fmri study, Neuropsychological Rehabilitation 15(3/4) (2005), 290-306.

[78] A.M. Owen, D.K. Menon, I.S. Johnsrude, D. Bor, S.K. Scott, T. Manly, E.J. Williams, C. Mummery and J.D. Pickard, Detecting residual cognitive function in persistent vegetative state, Neurocase 8(5) (2002), 394-403.

[79] A.M. Owen, N.D. Schiff and S. Laureys, A new era of coma and consciousness science, Prog Brain Res 177 (2009), 399341.

[80] C. Phillips, M. Bruno, P. Maquet, M. Boly, Q. Noirhomme, C. Schnakers, A. Vanhaudenhusye, M. Bonjean, R. Hustinx, G. Moonen, A. Luxen and S. Laureys, Relevance Vector Machine, consciousness classifier applied to cerebral metabolism of vegetative and locked-in patients, Neuroimage (2010).

[81] P. Qin, H. Di, Y. Liu, S. Yu, Q. Gong, N. Duncan, X. Weng, S. Laureys and G. Northoff, Anterior cingulate activity and the self in disorders of consciousness, Hum Brain Mapp (2010).

[82] M. Raichle and A. Snyder, A default mode of brain function: a brief history of an evolving idea, Neuroimage 37(4) (2007), 1083-1090.

[83] G. Rees, G. Kreiman and C. Koch, Neural correlates of consciousness in humans, Nat Rev Neurosci 3(4) (2002), 261270.

[84] M. Rousseau, S. Confort-Gouny, A. Catala, J. Graperon, J. Blaya, E. Soulier, P. Viout, D. Galanaud, Y. Le Fur, P. Cozzone and J. Ranjeva, A MRS-MRI-fMRI exploration of the brain. Impact of long-lasting persistent vegetative state, Brain Inj 22(2) (2008), 123-134.

[85] Royal College of Physicians of London, The vegetative state: guidance on diagnosis and management, Clin Med 3 (2003), 249-254.

[86] J. Rudolf, M. Ghaemi, W.F. Haupt, B. Szelies and W.D. Heiss, Cerebral glucose metabolism in acute and persistent vegetative state, Journal of Neurosurgical Anesthesiology 11(1) (1999), 17-24.
[87] J. Rudolf, J. Sobesky, M. Grond and W.D. Heiss, Identification by positron emission tomography of neuronal loss in acute vegetative state, Lancet 355 (2000), 155.

[88] N.D. Schiff, Multimodal neuroimaging approaches to disorders of consciousness, J Head Trauma Rehabil 21 (2006), 388-397.

[89] N.D. Schiff, J.T. Giacino, K. Kalmar, J. Victor, K. Baker, M. Gerber, B. Fritz, B. Eisenberg, T. Biond, J. O'Connor, E. Kobylarz, S. Farris, A. Machado, C. McCagg, F. Plum, J. Fins and I.A. Reza, Behavioural improvements with thalamic stimulation after severe traumatic brain injury, Nature 448(7153) (2007), 600-603.

[90] N.D. Schiff, U. Ribary, D.R. Moreno, B. Beattie, E. Kronberg, R. Blasberg, J. Giacino, C. McCagg, J.J. Fins, R. Llinas and F. Plum, Residual cerebral activity and behavioural fragments can remain in the persistently vegetative brain, Brain 125(Pt 6) (2002), 1210-1234.

[91] N.D. Schiff, D. Rodriguez-Moreno, A. Kamal, K.H. Kim, J.T. Giacino, F. Plum and J. Hirsch, fMRI reveals largescale network activation in minimally conscious patients, Neurology 64(3) (2005), 514-523.

[92] C. Schnakers, C. Chatelle, A. Vanhaudenhuyse, S. Majerus, D. Ledoux, M. Boly, M.A. Bruno, P. Boveroux, A. Demertzi, G. Moonen and S. Laureys, The Nociception Coma Scale: a new tool to assess nociception in disorders of consciousness, Pain 148(2) (2010), 215-219.

[93] C. Schnakers, J.T. Giacino, K. Kalmar, S. Piret, E. Lopez, M. Boly, R. Malone and S. Laureys, Does the FOUR score correctly diagnose the vegetative and minimally conscious states? Ann Neurol 60(6) (2006), 744-745.

[94] C. Schnakers, F. Perrin, M. Schabus, R. Hustinx, S. Majerus, G. Moonen, M. Boly, A. Vanhaudenhuyse, M.A. Bruno and S. Laureys, Detecting consciousness in a total locked-in syndrome: An active event-related paradigm, Neurocase (2009), $1-7$.

[95] C. Schnakers, F. Perrin, M. Schabus, S. Majerus, D. Ledoux, P. Damas, M. Boly, A. Vanhaudenhuyse, M.A. Bruno, G. Moonen and S. Laureys, Voluntary brain processing in disorders of consciousness, Neurology 71 (2008), 1614-1620.

[96] C. Schnakers, A. Vanhaudenhuyse, G.T. Giacino, M. Ventura, M. Boly, S. Majerus, G. Moonen and S. Laureys, Diagnostic accuracy of the vegetative and minimally conscious state: Clinical consensus versus standardized neurobehavioral assessment, BMC Neurology 9(35) (2009).

[97] C. Schnakers and N.D. Zasler, Pain assessment and management in disorders of consciousness, Curr Opin Neurol 20(6) (2007), 620-626.

[98] S. Silva, X. Alacoque, O. Fourcade, K. Samii, P. Marque, R. Woods, J. Mazziotta, F. Chollet and I. Loubinoux, Wakefulness and loss of awareness: brain and brainstem interaction in the vegetative state, Neurology 74(4) (2010), 313-320.

[99] A. Soddu, M. Boly, Y. Nir, Q. Noirhomme, A. Vanhaudenhuyse, A. Demertzi, A. Arzi, S. Ovadia, M. Stanziano, M. Papa, S. Laureys and R. Malach, Reaching across the abyss: recent advances in functional magnetic resonance imaging and their potential relevance to disorders of consciousness, Prog Brain Res 177 (2009), 261-274.

[100] W. Staffen, M. Kronbichler, M. Aichhorn, A. Mair and G. Ladurner, Selective brain activity in response to one's own name in the persistent vegetative state, J Neurol Neurosurg Psychiatry 77(12) (2006), 1383-1384.

[101] C. Tengvar, B. Johansson and J. Sorensen, Frontal lobe and cingulate cortical metabolic dysfunction in acquired akinetic 
mutism: a PET study of the interval form of carbon monoxide poisoning, BRAIN INJURY 18(6) (2004), 615-625.

[102] The Multi-Society Task Force on PVS, Medical aspects of the persistent vegetative state (1), N Engl J Med 330(21) (1994), 1499-1508.

[103] The Multi-Society Task Force on PVS, Medical aspects of the persistent vegetative state (2), N Engl J Med 330(22) (1994), 1572-1579.

[104] C. Tommasino, C. Grana, G. Lucignani, G. Torri and F. Fazio, Regional cerebral metabolism of glucose in comatose and vegetative state patients, J Neurosurg Anesthesiol 7(2) (1995), 109-116.

[105] L. Tshibanda, A. Vanhaudenhuyse, M. Boly, A. Soddu, M.A. Bruno, G. Moonen, S. Laureys and Q. Noirhomme, Neuroimaging after coma, Neuroradiology 52(1) (2010), 15-24.

[106] A. Vanhaudenhuyse, A. Demertzi, M. Schabus, Q. Noirhomme, S. Bredart, M. Boly, C. Phillips, A. Soddu, A. Luxen, G. Moonen and S. Laureys, Two Distinct Neuronal Networks Mediate the Awareness of Environment and of Self, J Cogn Neurosci (2010).

[107] A. Vanhaudenhuyse, J.T. Giacino, C. Schnakers, K. Kalmar, C. Smart, M.A. Bruno, O. Gosseries, G. Moonen and S. Laureys, Blink to visual threat does not herald consciousness in the vegetative state, Neurology (2008).

[108] A. Vanhaudenhuyse, Q. Noirhomme, L.J. Tshibanda, M.A.
Bruno, P. Boveroux, C. Schnakers, A. Soddu, V. Perlbarg, D. Ledoux, J.F. Brichant, G. Moonen, P. Maquet, M.D. Greicius, S. Laureys and M. Boly, Default network connectivity reflects the level of consciousness in non-communicative brain-damaged patients, Brain 133(Pt 1) (2010), 161-171.

[109] A. Vanhaudenhuyse, C. Schnakers, S. Bredart and S. Laureys, Assessment of visual pursuit in post-comatose states: use a mirror, J Neurol Neurosurg Psychiatry 79(2) (2008), 223.

[110] B.A. Vogt, L. Vogt and S. Laureys, Cytology and functionally correlated circuits of human posterior cingulate areas, Neuroimage 29(2) (2006), 452-466.

[111] B.A. Vogt and S. Laureys, Posterior cingulate, precuneal and retrosplenial cortices: cytology and components of the neural network correlates of consciousness, Prog Brain Res 150 (2005), 205-217.

[112] H.U. Voss, A.M. Uluc, J.P. Dyke, R. Watts, E.J. Kobylarz, B.D. McCandliss, L.A. Heier, B.J. Beattie, K.A. Hamacher, S. Vallabhajosula, S.J. Goldsmith, D. Ballon, J.T. Giacino and N.D. Schiff, Possible axonal regrowth in late recovery from the minimally conscious state, J Clin Invest 116(7) (2006), 2005-2011.

[113] J. Zhu, X. Wu, L. Gao, Y. Mao, P. Zhong, W. Tang and L. Zhou, Cortical activity after emotional visual stimulation in minimally conscious state patients, J Neurotrauma 26(5) (2009), 677-688. 